\title{
Optimization of the Operative Conditions for Heteropolyacids Synthesis through Ion Exchange
}

\author{
Silvana Raquel Matkovic, Graciela Manuela Valle, Laura Estefania Briand* \\ Centro de Investigación y Desarrollo en Ciencias Aplicadas \\ Dr. J. J. Ronco, CONICET, Universidad Nacional de La Plata, \\ Calle $47 N^{\circ}$ 257, B1900AJK La Plata, Buenos Aires, Argentina
}

Received: January 18, 2005; Revised: May 2, 2005

\begin{abstract}
Phospho-tungstic and phospho-molybdic Wells-Dawson heteropolyacids, $\mathrm{H}_{6} \mathrm{P}_{2} \mathrm{~W}_{18} \mathrm{O}_{62} \cdot \mathrm{xH}_{2} \mathrm{O}$ and $\mathrm{H}_{6} \mathrm{P}_{2} \mathrm{Mo}_{18} \mathrm{O}_{62} \cdot \mathrm{xH}_{2} \mathrm{O}$ respectively, were synthesized through ion exchange with a higher yield $(\sim 90 \%)$ than the conventional organic route $(\sim 70 \%)$. Pure, non-degraded heteropolyacids are obtained when the corresponding ammonium salt $\left[\left(\mathrm{NH}_{4}\right)_{6} \mathrm{P}_{2} \mathrm{~W}_{18} \mathrm{O}_{62} \cdot 13 \mathrm{H}_{2} \mathrm{O}\right.$ or $\left.\left(\mathrm{NH}_{4}\right)_{6} \mathrm{P}_{2} \mathrm{Mo}_{18} \mathrm{O}_{62} \cdot 12 \mathrm{H}_{2} \mathrm{O}\right]$ is kept in contact with an acid resin [about (1:0.8) salt:resin weight ratio] up to three days. The use of an organic media instead of an aqueous media greatly favors the completeness of the exchange.
\end{abstract}

Keywords: Wells-Dawson, heteropolyacid, POM, HPA

\section{Introduction}

Heteropoly-anions $\left[\mathrm{X}_{\mathrm{y}} \mathrm{M}_{\mathrm{x}} \mathrm{O}_{\mathrm{m}}\right]^{\mathrm{n}-}$ are composed of a close-packed framework of metal-oxygen octahedrons, $\mathrm{M}-\mathrm{O}\left(\mathrm{M}=\mathrm{Mo}^{6+}, \mathrm{W}^{6+}\right.$, $\left.\mathrm{V}^{5+}\right)$ surrounding a central atom, $\mathrm{X}\left(\mathrm{Si}^{4+}, \mathrm{P}^{5+}, \text { etc }\right)^{1}$. Nowadays, much research is focused on Keggin $\left[\mathrm{XM}_{12} \mathrm{O}_{40}\right]^{3-}$ and Wells-Dawson-type $\left[\mathrm{X}_{2} \mathrm{M}_{18} \mathrm{O}_{62}\right]^{6-}$ anions due to their promising application as catalytic materials $^{2,3}$. The free acid form of the heteropoly-anions, i.e. Keggin $\mathrm{H}_{3} \mathrm{XM}_{12} \mathrm{O}_{40}$ and Wells-Dawson $\mathrm{H}_{8} \mathrm{X}_{2} \mathrm{M}_{18} \mathrm{O}_{62}$ type compounds, are solid superacids since their acid strength is greater than that of $100 \% \mathrm{H}_{2} \mathrm{SO}_{4}$. Therefore, many heteropolyacids are more active catalysts than conventional organic and inorganic acids in liquidphase reaction. The insolubility of the heteropoly-acids in many organic substances allows an easy separation and reutilization of these catalysts. Moreover, several liquid-phase processes showed that the reaction mixture separates in two phases, one of those containing the heteropoly-compound ${ }^{3,4}$.

Undoubtedly, the catalytic processes based on heteropolyacids are an outstanding contribution in the development of environmental benign technologies. However, the synthesis of these compounds is rather complicated, involves the use of dangerous chemicals and produces harmful liquid and gaseous wastes.

Phospho-tungstic $\mathrm{H}_{6} \mathrm{P}_{2} \mathrm{~W}_{18} \mathrm{O}_{62} \cdot 24 \mathrm{H}_{2} \mathrm{O}$, phospho-molybdic $\mathrm{H}_{6} \mathrm{P}_{2} \mathrm{Mo}_{18} \mathrm{O}_{62} \cdot \mathrm{nH}_{2} \mathrm{O}(\mathrm{n}=33-37)$ and arsenic-molybdic $\mathrm{H}_{6} \mathrm{As}_{2} \mathrm{Mo}_{18} \mathrm{O}_{62} \cdot \mathrm{nH}_{2} \mathrm{O}(\mathrm{n}=25-35)$ Wells-Dawson acids have been synthesized $^{5-10}$.

The heteropolyacids are synthesized through the "etherate method", electrodialysis, ion exchange and precipitation with sulfuric acid ${ }^{11}$.

The "etherate method" requires a strongly acidified aqueous solution of the heteropolyanion (from an aqueous soluble heteropoly-salt) that is shaken with diethyl ether in order to separate three phases: an upper ether layer, an aqueous layer and a heavy oily layer. This layer contains an etherate of the heteropolyacid of unknown composition. The etherate is decomposed with water and the solution is evaporated until the acid crystallizes. According to early studies by $\mathrm{Wu}$ and our own experience, this method does not yield pure $\mathrm{H}_{6} \mathrm{P}_{2} \mathrm{Mo}_{18} \mathrm{O}_{62} \cdot \mathrm{nH}_{2} \mathrm{O}$ but a mixture with phospho-molybdic Keggintype acid $\mathrm{H}_{3} \mathrm{PMo}_{12} \mathrm{O}_{40}{ }^{12}$.
This technique requires expensive and dangerous chemicals, possesses a low yield towards the acid, produces an important amount of harmful wastes (highly acid organic liquid) and is time consuming.

Maksimov et al. applied electrodialysis to synthesize iso and heteropoly acids of various structures in highly concentrated aqueous solutions ${ }^{13}$. In general, this method avoids the use of diethyl ether and inorganic acids since the solution is electrochemically acidified during operation. However, the synthesis of the $\mathrm{H}_{6} \mathrm{P}_{2} \mathrm{~W}_{18} \mathrm{O}_{62}$ is rather complicated since it requires the electrodialysis of a mixture of $\mathrm{H}_{3} \mathrm{PO}_{4}$ and $\mathrm{Na}_{2} \mathrm{WO}_{4}$ up to a certain $\mathrm{pH}$ value, then a thermal treatment (6 hours at $150{ }^{\circ} \mathrm{C}$ ) and dialysis again to obtain the desired product.

More recently, Wijesekera et al. patented the synthesis of phospho-molybdic Wells-Dawson-type polyoxometallates through an ion exchange methodology in aqueous media ${ }^{14,15}$. Interestingly, the authors synthesized the phospho-molybdic Wells-Dawson acid through ion exchange in a column into an ice bath. However, the effect of the temperature on the synthesis or the flow rate of the effluent was not discussed.

The present investigation presents a detailed examination of the conditions (solvents, substrate-resin ratio, time of the exchange and temperature) to optimize the synthesis of phospho-tungstic and phospho-molybdic Wells-Dawson acids through the ion exchange method both batchwise and in column.

\section{Experimental}

$$
\begin{aligned}
& \text { 2.1. Synthesis of the }\left(\mathrm{NH}_{4}\right)_{6} \mathrm{P}_{2} \mathrm{~W}_{18} \mathrm{O}_{62} \cdot 13 \mathrm{H}_{2} \mathrm{O} \text { and } \\
& \left(\mathrm{NH}_{4}\right)_{6} \mathrm{P}_{2} \mathrm{Mo}_{18} \mathrm{O}_{62} \cdot 12 \mathrm{H}_{2} \mathrm{O} \text { salts }
\end{aligned}
$$

Heteropoly acids were synthesized through ion exchange of the phospho-tungstic $\left(\mathrm{NH}_{4}\right)_{6} \mathrm{P}_{2} \mathrm{~W}_{18} \mathrm{O}_{62} .13 \mathrm{H}_{2} \mathrm{O}$ and molybdic ammonium salts $\left(\mathrm{NH}_{4}\right)_{6} \mathrm{P}_{2} \mathrm{Mo}_{18} \mathrm{O}_{62} \cdot 12 \mathrm{H}_{2} \mathrm{O}$ with an ion exchange resin.

The ammonium phospho-tungstic Wells-Dawson salt was synthesized according to the method reported by Lyon et al. ${ }^{16}$. Concentrated $\mathrm{H}_{3} \mathrm{PO}_{4}$ (Merck ACS, 85\%) was added to a boiling solution of $\mathrm{Na}_{2} \mathrm{WO}_{4}$ (J. T. Baker ACS, $100 \%$ ) in a $4: 1$ acid:salt molar ratio. The mixture was kept boiling under stirring for 8 hours. Ammonium chloride 
$\mathrm{NH}_{4} \mathrm{Cl}$ (J. T. Baker ACS, 100\%) was added in order to precipitate the salt. The salt with the mother liquor was kept overnight at $5{ }^{\circ} \mathrm{C}$ to improve the yield of the precipitation process. The salt was dissolved in water at room temperature and filtered to remove impurities. Again, ammonium chloride was added to re-precipitate the salt and the solution was kept at low temperature overnight. Finally, the salt was filtered, washed with water and dried under vacuum at room temperature.

The ammonium phospho-molybdic Wells-Dawson salt was synthesized with $\mathrm{Na}_{2} \mathrm{MoO}_{4}, \mathrm{H}_{3} \mathrm{PO}_{4}$ and $\mathrm{HCl}$ according to a method published before ${ }^{17}$.

Additionally, the phospho-tungstic Wells-Dawson acid $\mathrm{H}_{6} \mathrm{P}_{2} \mathrm{~W}_{18} \mathrm{O}_{62}$ was synthesized according to the "etherate method" from a $\alpha / \beta-\mathrm{K}_{6} \mathrm{P}_{2} \mathrm{~W}_{18} \mathrm{O}_{62}$ isomer mixture. The details of the synthesis have been published previously ${ }^{8}$. The yield of this method is $71.4 \%$.

\subsection{Additional materials and methods}

A Dowex HCR-W2 (Sigma-Aldrich) acid resin was used in the ion exchange experiments. This material possesses a $1.9 \mathrm{meq} / \mathrm{ml}$ exchange capacity according to the vendor. The density of the wet resin was determined as $1.2 \mathrm{~g} / \mathrm{ml}$ which results in a $2.4 \mathrm{meq} / \mathrm{g}$ exchange capacity.

The starting ammonium salts were dissolved in absolute ethanol (Merck, 99.8\%) or distilled water prior to the contact with the resin.

The ion exchange experiments were performed both in a column and batchwise. The flow rate of the effluent in the column experiments was calculated as the ratio of the volume of effluent collected per unit of time and volume of wet resin (BV/min).

The resultant solution after the exchange was allowed to dry at room temperature prior to the analysis.

\subsection{Infrared spectroscopy}

The presence of the ammonium ion after the exchange and the stability of the Wells-Dawson structure were followed through infrared spectroscopy. The analysis was performed with a FTIR Bruker IFS 66 equipment under ambient conditions. The solid samples were diluted with $\mathrm{KBr}$ and pressed into thin wafers.

\subsection{Nuclear magnetic resonance ${ }^{31} P$ NMR}

The purity of the Wells-Dawson structure was followed through nuclear magnetic resonance of phosphorous. Liquid NMR spectra were obtained with a Bruker AM 500 spectrograph both in $\mathrm{D}_{2} \mathrm{O}$ and deutered methanol $\mathrm{CD}_{3} \mathrm{OD}$ under ambient conditions. The equipment operates at a frequency of $202.458 \mathrm{MHz}$ with $11.3 \mu$ s pulses. The analysis involved 8-800 pulse responses with a resolution of $0.25 \mathrm{~Hz}$ per point.

\section{Results and Discussion}

The influence of the operation conditions such as, amount of resin (salt:resin weight ratio), nature of the solvent, temperature and time in the exchange of ammonium by protons ions were investigated in batch experiments.

Figures 1 and 2 show the infrared spectra of the materials obtained through the ion exchange of the ammonium phospho-tungstic Wells-Dawson salt $\left(\mathrm{NH}_{4}\right)_{6} \mathrm{P}_{2} \mathrm{~W}_{18} \mathrm{O}_{62} .13 \mathrm{H}_{2} \mathrm{O}$ in aqueous and organic media in batch experiments, respectively. A great variety of conditions were tested however, only the most representative results of the experiments are included in order to simplify the discussion. Additionally, the spectrum of the phospho-tungstic Wells-Dawson acid $\mathrm{H}_{6} \mathrm{P}_{2} \mathrm{~W}_{18} \mathrm{O}_{62} .24 \mathrm{H}_{2} \mathrm{O}$ synthesized through the "etherate method" and the starting ammonium salt are presented for comparison.

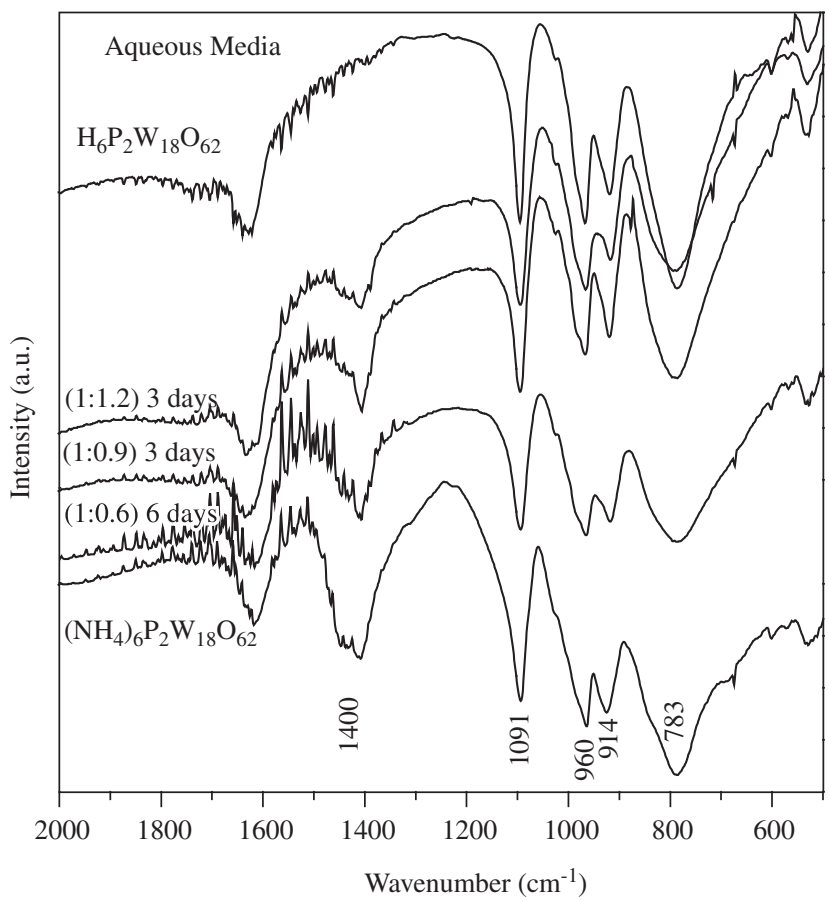

Figure 1. Infrared spectra of the $\left(\mathrm{NH}_{4}\right)_{6} \mathrm{P}_{2} \mathrm{~W}_{18} \mathrm{O}_{62} \cdot 13 \mathrm{H}_{2} \mathrm{O}$ salt, the $\mathrm{H}_{6} \mathrm{P}_{2} \mathrm{~W}_{18} \mathrm{O}_{62} \cdot 24 \mathrm{H}_{2} \mathrm{O}$ heteropolyacid obtained through the conventional organic method and the materials obtained through the ion exchange of the salt in aqueous media under variable (salt:resin) weight ratios and time of exchange.

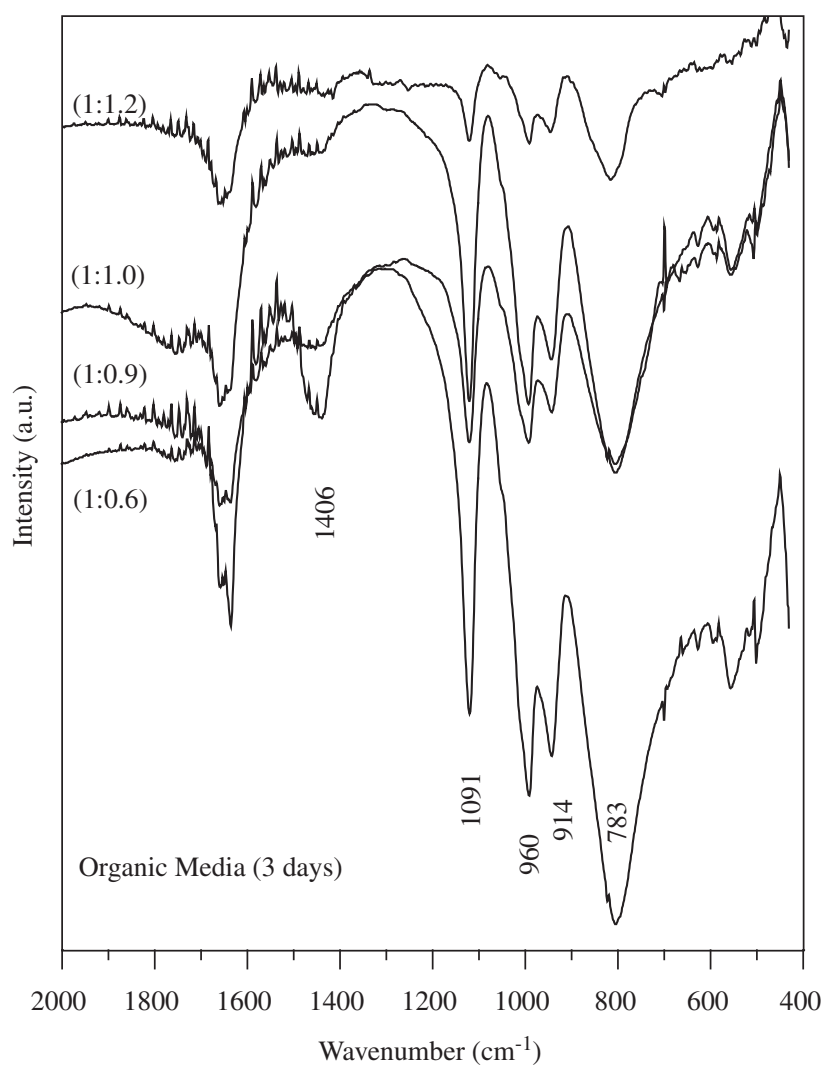

Figure 2. Infrared spectra of the materials obtained through the ion exchange of the $\left(\mathrm{NH}_{4}\right)_{6} \mathrm{P}_{2} \mathrm{~W}_{18} \mathrm{O}_{62} .13 \mathrm{H}_{2} \mathrm{O}$ salt after 3 days in contact with variable amounts of acid resin in ethanol media. The numbers in parenthesis represent the (salt: resin) weight ratios. 
The experiments were carried at a starting (1:0.6) salt:resin weight ratio that corresponds to the stoichiometric exchange ratio. That is $1.00 \mathrm{~g}$ of $\left(\mathrm{NH}_{4}\right)_{6} \mathrm{P}_{2} \mathrm{~W}_{18} \mathrm{O}_{62} \cdot 13 \mathrm{H}_{2} \mathrm{O}$ salt $(\mathrm{MW} .4708 \mathrm{~g} / \mathrm{mol}$, $6 \times 10^{-3} \mathrm{meq} / \mathrm{mol}$ ) possesses $1.27 \mathrm{meq}$ that requires $0.60 \mathrm{~g}$ of resin (the resin possesses $2.40 \mathrm{meq} / \mathrm{g}$ exchange capacity).

The spectra of the phospho-tungstic Wells-Dawson acid possess an intense band at $1091 \mathrm{~cm}^{-1}$ assigned to the stretching mode of the $\mathrm{P}-\mathrm{O}$ species. This band is considered a fingerprint of the Wells-Dawson heteropolyanion $\mathrm{P}_{2} \mathrm{~W}_{18} \mathrm{O}_{62}{ }^{6-}$ structure. The bands at 960, 914 and $783 \mathrm{~cm}^{-1}$ correspond to the W-O species of the cage structure surrounding the central phosphorous species ${ }^{8}$.

The spectra of the Wells-Dawson salt before and after being in contact with the acid resin in aqueous media possess a band at $1400 \mathrm{~cm}^{-1}$ that corresponds to $\mathrm{NH}_{4}^{+}$species. The presence of this band in all the experiments carried in aqueous media indicates that the exchange was not complete regardless of the amount of resin and the time of the exchange.

The exchange in organic media were carried up to three days since the experiments in aqueous media demonstrated that extended contact with the resin results in a reversible exchange of ammonium (spectra not shown).

Figure 2 shows the exchange of the ammonium phospho-tungstic salt in contact with various amounts of resin in ethanol media. The absence of the band corresponding to ammonium species indicates that the exchange is complete at (1:0.9) salt:resin weight ratio. The yield of this synthesis was $95.5 \%$ which results higher than the "etherate" route for the phospho-tungstic acid (see section 2.1).

${ }^{31} \mathrm{P}$ NMR analysis was not useful to determine the effectiveness of the exchange since both the starting ammonium phospho-tungstic Wells-Dawson salt and the acid possess similar signals at $-10.78 \mathrm{ppm}$, - $11.55 \mathrm{ppm}$ and - $12.28 \mathrm{ppm}$ which makes difficult to distinguish both substances.

The experiments with the ammonium phospho-molybdic salt in batch with various salt:resin weight ratios demonstrated that a complete exchange is achieved with the stoichiometric (1:0.8) exchange ratio $\left[\left(\mathrm{NH}_{4}\right)_{6} \mathrm{P}_{2} \mathrm{Mo}_{18} \mathrm{O}_{62} \cdot 12 \mathrm{H}_{2} \mathrm{O}\right.$ MW. $\left.3106 \mathrm{~g} / \mathrm{mol}, 610^{-3} \mathrm{meq} / \mathrm{mol}\right]$ (data not shown). Therefore, this ratio was kept constant while the effect of the nature of the solvent and the temperature in the exchange effectiveness was investigated.

Figures 3 and 4 show the effect of time and temperature (room temperature and $5{ }^{\circ} \mathrm{C}$ ) in the ion exchange of the ammonium phospho-molybdic Wells-Dawson salt in aqueous and organic media, respectively. The spectra of the starting Wells-Dawson salt $\left(\mathrm{NH}_{4}\right)_{6} \mathrm{P}_{2} \mathrm{Mo}_{18} \mathrm{O}_{62} \cdot 12 \mathrm{H}_{2} \mathrm{O}$ possesses the characteristic signals of the central phosphorous species at $1078 \mathrm{~cm}^{-1}$ and $904 \mathrm{~cm}^{-1}$, and Mo-O species at $\sim 936 \mathrm{~cm}^{-1}$ and $769 \mathrm{~cm}^{-1} 17,18$. Additionally, the ammonium salt possesses the infrared signal of the $\mathrm{NH}_{4}^{+}$species at $1403 \mathrm{~cm}^{-1}$ similarly to the phospho-tungstic salt.

Again, the comparison of the infrared spectra of the materials obtained in aqueous and ethanol media indicate that the ion exchange is greatly favored in organic media. In fact the phospho-molybdic acid is obtained after three days of ion exchange with a $92.2 \%$ yield. Moreover, the experiments demonstrated that the temperature does not influence the exchange.

Nuclear magnetic resonance of phosphorous ${ }^{31} \mathrm{P}$ further confirmed the complete exchange of the ammonium species. The ammonium phospho-molybdic Wells-Dawson salt possesses a single signal at $-1.596 \mathrm{ppm}$ that is replaced by another signal at -1.665 ppm (characteristic signal of the acid in $\mathrm{CD}_{3} \mathrm{OD}$ ) belonging to the phospho-molybdic Wells-Dawson acid when the exchange is complete. The ${ }^{31} \mathrm{P}$ NMR analysis of the pure acid in $\mathrm{D}_{2} \mathrm{O}$ showed also an intense signal at $-2.419 \mathrm{ppm}$ (spectra not shown). However, the phospho-molybdic acid obtained through ion exchange

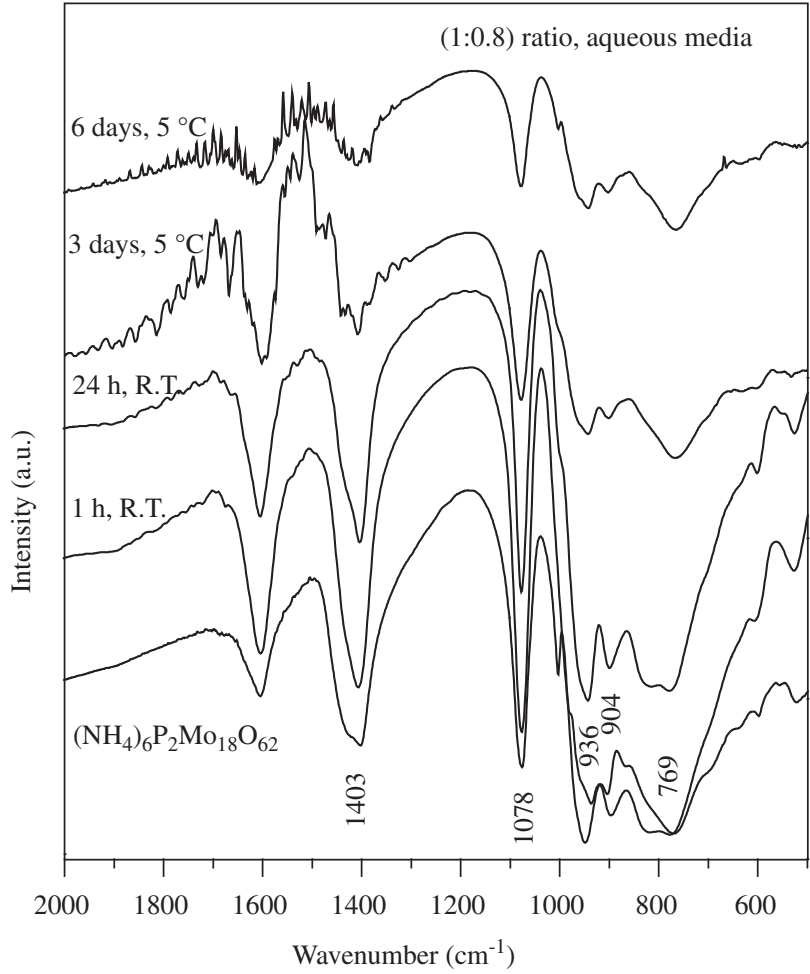

Figure 3. Infrared spectra of the $\left(\mathrm{NH}_{4}\right)_{6} \mathrm{P}_{2} \mathrm{Mo}_{18} \mathrm{O}_{62} .12 \mathrm{H}_{2} \mathrm{O}$ salt and the materials obtained through the ion exchange of the salt in contact with (1:0.8) salt:resin weight ratio and variable time and temperature of exchange in aqueous media.

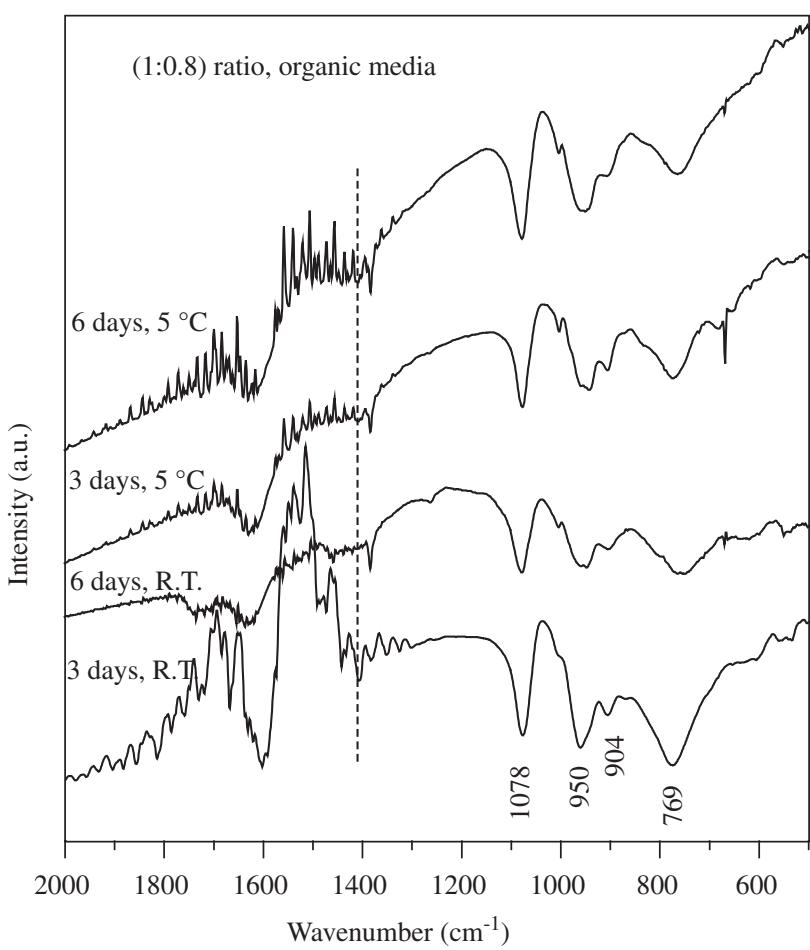

Figure 4. Infrared spectra of the materials obtained through the ion exchange of the $\left(\mathrm{NH}_{4}\right)_{6} \mathrm{P}_{2} \mathrm{Mo}_{18} \mathrm{O}_{62} .12 \mathrm{H}_{2} \mathrm{O}$ salt in contact with (1:0.8) salt:resin weight ratio and variable time and temperature of exchange in ethanol media. The dash line indicates the position of the ammonium species. 
in aqueous media and ethanol shows traces of Keggin species at - $3.988 \mathrm{ppm}$.

The phospho-molybdic Wells-Dawson heteropolyanion $\mathrm{P}_{2} \mathrm{Mo}_{18} \mathrm{O}_{62}^{6-}$ is not stable in aqueous media at difference with the phospho-tungstic structure that maintains intact regardless of the nature of the solvent. Previous studies demonstrated that the phosphomolybdic Wells-Dawson heteropolyanion $\mathrm{P}_{2} \mathrm{Mo}_{18} \mathrm{O}_{62}{ }^{6-}$ decomposes in the Keggin-type anion $\mathrm{H}_{x} \mathrm{PMo}_{12} \mathrm{O}_{40}{ }^{(3-x)-}$, pentamolybdodiphosphate $\mathrm{H}_{\mathrm{x}} \mathrm{P}_{2} \mathrm{Mo}_{5} \mathrm{O}_{23}{ }^{(6-x)-}$ and heptamolybdate $\mathrm{Mo}_{7} \mathrm{O}_{24}{ }^{6-}$ or molybdate $\mathrm{MoO}_{4}{ }^{2-}$ species ${ }^{17,18}$. The present investigation shows that the ion exchange process leads to a minimum degradation of the WellsDawson anion towards the Keggin $\mathrm{PMo}_{12} \mathrm{O}_{40}{ }^{3-}$ anion regardless of the medium.

Additionally, the ion exchange was carried in a glass column with a (1:3) salt:resin weight ratio. The experiments were performed with a flow rate varying from 0.8 to $3.6 \mathrm{BV} / \mathrm{min}$ due to the fact that this parameter was difficult to reproduce from one experiment to another. This is a typical drawback of the exchange columns that possesses a regular two-ways stopcock.

Figure 5 show the infrared spectra of the materials obtained after the ion exchange of the phospho-tungstic and phospho-molybdic ammonium salts dissolved in the minimum amount of water or ethanol. The aqueous solution of the molybdic salt was prepared in the minimum amount of cold water and the column was packed in an ice bath similarly to the experiments performed by Wijesekera et al. ${ }^{15}$.

The exchange of the phospho-tungstic salt was complete when the experiment was carried in aqueous medium but not in ethanol. However, the exchange of the molybdenum based salt was not successful regardless of the solvent or the flow rate. Again, the temperature does not show any positive influence in the exchange. Moreover, the

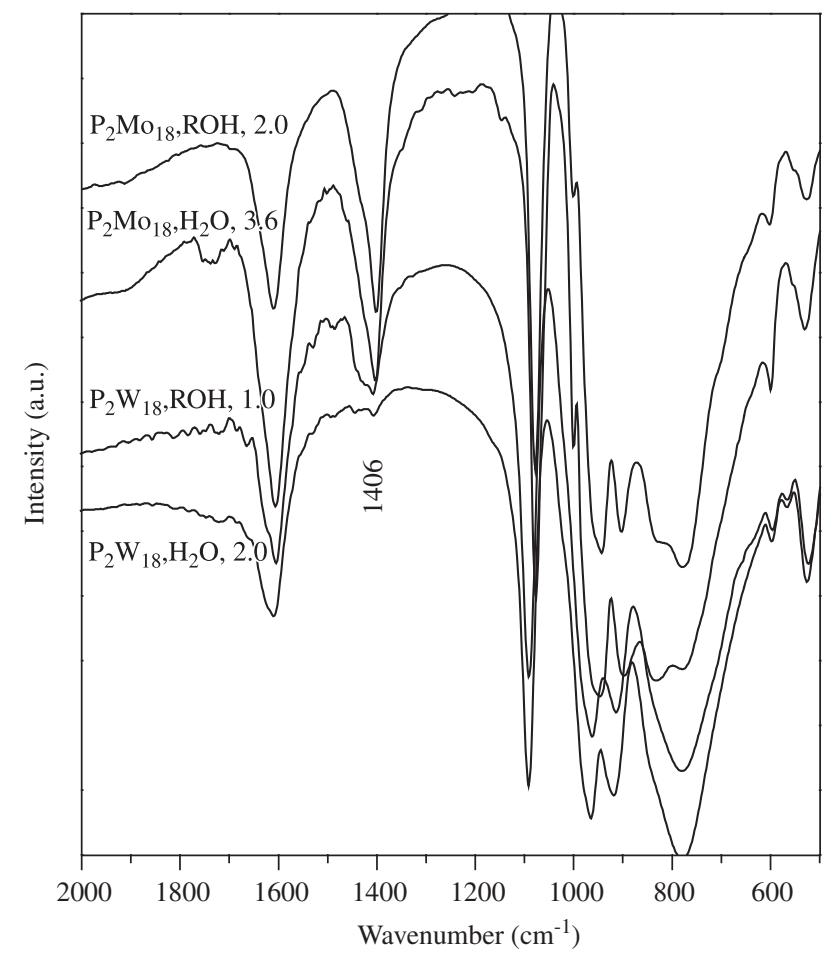

Figure 5. Infrared spectra of the materials obtained through the ion exchange of the $\left(\mathrm{NH}_{4}\right)_{6} \mathrm{P}_{2} \mathrm{~W}_{18} \mathrm{O}_{62} .13 \mathrm{H}_{2} \mathrm{O}$ and $\left(\mathrm{NH}_{4}\right)_{6} \mathrm{P}_{2} \mathrm{Mo}_{18} \mathrm{O}_{62} .12 \mathrm{H}_{2} \mathrm{O}$ salts in a column containing (1:3) salt:resin weight ratio. The spectra are labeled with the name of the starting salt $\left(\mathrm{P}_{2} \mathrm{~W}_{18}\right.$ and $\mathrm{P}_{2} \mathrm{Mo}_{18}$ for brevity), the solvent [aqueous and ethanol (ROH) media] and the flow rate of the effluent (BV/min). discrepancy between these results and those reported by Wijesekera et al. might be ascribed to the contact time of the solution with the resin. In fact, the flow rate of the solution through the resin does have a key role in the exchange equilibrium as shown in the experiments carried batchwise.

\section{Conclusions}

The present investigation demonstrates that the ion exchange methodology is suitable to be used for the synthesis of phosphotungstic and molybdic Wells-Dawson acids in a higher yield than the conventional organic route.

In general, pure, non-degraded acids are obtained through the ion exchange of the ammonium salt counterpart with a highly acidic resin in ethanol. The experiments indicated that the use of an organic media greatly favors the ion exchange since a lower amount of resin is required than in aqueous media.

The comparison of the experiments performed batchwise and in column demonstrated that the contact time between the salt and the resin is also a key factor in the exchange equilibrium. An optimum contact of three days was observed for the completeness of the exchange carried in batch. Although the use of a column might greatly diminish the time required for the exchange, the flow rate must be carefully controlled and is difficult to reproduce between experiments. Moreover, a higher amount of resin is needed compared with a batch technique.

\section{Acknowledgments}

The authors acknowledge the financial support provided by Consejo Nacional de Investigaciones Científicas y Técnicas CONICET (PEI No 6132); Agencia Nacional de Promoción Científica y Tecnológica (PICT 14-12161/02) and Universidad Nacional de La Plata (project X378).

\section{References}

1. Mizuno N, Misono M. Heterogeneous catalysis. Chem. Rev. 1998; 98(1):199-217.

2. Okuhara, T, Mizuno N, Misono M. Catalytic chemistry of heteropoly compounds. Adv. Catal. 1996; 41:113-252.

3. Briand LE, Baronetti GT, Thomas HJ. The state of the art on Wells-Dawson heteropoly-compounds. A review of their properties and applications. Appl. Catal. 2003; 256(1-2):37-50.

4. Vázquez P, Pizzio L, Cáceres C, Blanco M, Thomas H, Alesso E, Finkielsztein L, Lantaño B, Moltrasio G, Aguirre J. Silica-supported heteropolyacids as catalysts in alcohol dehydration reactions. J. Mol. Catal. A: Chemical. 2000; 161(1-2):223-232.

5. Pope MT, Papaconstantinou E. Heteropoly blues. II Reduction of 2:28 tungstates. Inorg. Chem. 1967; 6(6):1147-1152.

6. Lunk HJ, Varfolomeev MB, Hilmer W. The thermal decomposition of $\mathrm{H}_{6} \mathrm{P}_{2} \mathrm{~W}_{18} \mathrm{O}_{62} \cdot 31 \mathrm{H}_{2} \mathrm{O}$. Russ. J. Inorg. Chem. 1983; 28(4):529-530.

7. Shikata S, Nakata S, Okuhara T, Misono M. Catalysis by heteropoly compounds. 32. Synthesis of methyl tert-butyl ether catalyzed by heteropolyacids supported on silica. J. Catal. 1997; 166(2):263-271.

8. Baronetti G, Briand L, Sedran U, Thomas H. Heteropolyacid-based catalysis. Dawson acid for MTBE synthesis in gas phase. Appl. Catal. 1998; 172(2):265-272.

9. Baronetti G, Thomas H, Querini CA. Wells-Dawson heteropolyacid supported on silica: isobutane alkylation with C4 olefins. Appl. Catal. 2001; 217(1-2):131-141.

10. Kozhevnikov IV, Kloestra KR, Sinnema A, Zandgergen HW, van Bekkum $\mathrm{H}$. Study of catalysts comprising heteropoly acid $\mathrm{H}_{3} \mathrm{PW}_{12} \mathrm{O}_{40}$ supported on MCM-41 molecular sieve and amorphous silica. J. Mol. Catal. 1996; 114(1-3): 287-298. 
11. Pope MT. Heteropoly and Isopoly Oxometalates. Berlin: Springer-Verlag, 1983.

12. Wu H. Contribution to the chemistry of phosphomolybdic acids, phosphotungstic acids, and allied substances. J. Biol. Chem. 1920; 43(1):189-220.

13. Maksimov GM, Maksimovskaya RI, Kozhevnikov IV. Application of electrodialysis to synthesis of heteropolyacids. Russ. J. Inorg. Chem.1994; 39(4):595-600.

14. Wijesekera TP, Lyons JE, Ellis Jr (2000). Wells-Dawson heteropolyacids, their preparation and use as oxidation catalysts. US Patent, us $6,060,419$.
15. Wijesekera TP, Lyons JE, Ellis Jr (2001). Wells-Dawson heteropolyacids, their preparation and use as oxidation catalysts. US Patent, us $6,169,202$.

16. Lyon DK, Miller WK, Novet T, Domaille PJ, Evitt E, Johnson DC, Finke R. Highly oxidation resistant inorganic-porphyrin analogue polyoxometalate oxidation catalysts. 1 . The synthesis and characterization of aqueoussoluble potassium salts of $\alpha_{2}-\mathrm{P}_{2} \mathrm{~W}_{17} \mathrm{O}_{61}\left(\mathrm{M}^{\mathrm{n}+} \cdot \mathrm{OH}_{2}\right)^{(\mathrm{n}-1)}$ and organic solvent soluble tetra n-butylammonium salts $\alpha_{2}-\mathrm{P}_{2} \mathrm{~W}_{17} \mathrm{O}_{61}\left(\mathrm{M}^{\mathrm{n}+} \cdot \mathrm{Br}\right)^{(\mathrm{n}-11)}\left(\mathrm{M}=\mathrm{Mn}^{3+}\right.$, $\left.\mathrm{Fe}^{3+}, \mathrm{Co}^{2+}, \mathrm{Ni}^{2+}, \mathrm{Cu}^{2+}\right)$. J. Am. Chem. Soc. 1991; 113(19):7209-7221.

17. Briand LE, Valle GM, Thomas HJ. Stability of the phospho-molybdic Dawson-type ion $\mathrm{P}_{2} \mathrm{Mo}_{18} \mathrm{O}_{62}{ }^{6-}$ in aqueous media. J. Mater. Chem. 2002; 12(2):299-304

18. Valle GM, Briand LE. Stability of phospho-molybdic WellsDawson-type ion $\mathrm{P}_{2} \mathrm{Mo}_{18} \mathrm{O}_{62}{ }^{6-}$ in organic media. Mat. Lett. 2003; 57(24-25):3964-3969. 